\title{
Comparison of body mass index and body surface area as outcome predictors in patients with systolic heart failure
}

\author{
Barak Zafrir ${ }^{1}$, Yaron Goren ${ }^{2}$, Nabeeh Salman³, Offer Amir ${ }^{3}$ \\ ${ }^{1}$ Department of Cardiovascular Medicine, Lady Davis Carmel Medical Center \\ and Heart Failure Clinic, Lin Medical Center, Haifa, Israel \\ ${ }^{2}$ Sackler School of Medicine, Tel Aviv University, Tel Aviv, Israel \\ ${ }^{3}$ Cardio-Vascular Division, Poriya Medical Center, Tiberius, Israel
}

\begin{abstract}
Background: We investigated whether the 'obesity paradox' in heart failure (HF) is influenced by common confounders, and assessed if body surface area (BSA) may correlate more closely than body mass index (BMI) with prognosis.

Methods: We studied 630 systolic HF patients at their initial visit to the HF clinic. Body size was measured by BMI and BSA. The association between body indices and mortality was assessed by Cox proportional-hazard analyses.
\end{abstract}

Results: There were 248 deaths during mean follow-up of 39 months. A progressive inverse association of BMI and BSA tertiles (T1-T3) with mortality risk was observed (for BSA: T3, reference, T2, hazard ratio $[H R] 1.41,95 \%$ confidence interval $[C I] 1.01-1.95, p=0.04$ and $T 1, H R=1.78,95 \%$ CI 1.29-2.45, $p<0.001$; for BMI: T3, reference, T2, HR $=1.29,95 \%$ CI $0.92-1.79, p=0.13$ and T1, HR $=1.66,95 \%$ CI 1.21-2.27, $p=0.002$ ). The obesity paradox was attenuated after multivariate adjustment, and did not persist after adjustment for age alone (for BMI: T3, reference, T2, HR $=1.13,95 \%$ CI 0.81-1.58, $p=0.47 ; T 1, H R=1.30,95 \%$ CI 0.94-1.80, $p=0.12$; for BSA: T3, reference, T2, HR =0.96, 95\% CI 0.68-1.35, $p=0.82$; $T 1, H R=1.15,95 \%$ CI 0.82-1.63, $p=0.42$ ).

Conclusions: BSA provides prognostic information similar to BMI in systolic HF. However, the obesity paradox of both BMI and BSA in HF may be confounded by the younger age of the obese patients. (Cardiol J 2015; 22, 4: 375-381)

Key words: systolic heart failure, body mass index, body surface area, prognosis, confounding factors

\section{Editorial p. 357}

\section{Introduction}

Obesity adversely impacts cardiovascular (CV) risk factors as well as left ventricular structure and function. Accordingly, it is an established risk factor for the development of $\mathrm{CV}$ diseases including heart failure (HF) [1-3]. However, numerous studies have demonstrated over the years that in patients with existing HF, obesity is unexpectedly associated with better survival [4-9]. This notion that overweight and obese individuals have

Address for correspondence: Barak Zafrir, MD, Cardiovascular Department, Lady Davis Carmel Medical Center, 7 Michal st., Haifa, Israel, tel: +972-48250285, fax: +972-99560390, e-mail: barakzmd@gmail.com 
survival advantage compared with leaner subjects was reported in addition to HF in several other chronic CV disease conditions and is named the 'obesity paradox' $[10,11]$.

Several potential mechanisms trying to explain the obesity paradox in $\mathrm{HF}$ are suggested in the literature [12]. These include among others, the effects of cardiac cachexia, catabolic state and muscle wasting in lean HF subjects, in contrast to greater metabolic reserve and increased muscle mass and strength in overweight and obese HF individuals. In addition, it is implicated that confounding factors which are unmeasured or not fully adjusted for, may account for the inverse relationship between obesity and mortality seen in HF cohorts [13]. These factors include variance in the prevalence of comorbidities in the obese vs. lean HF subjects, such as higher blood pressures allowing for more cardiac medications, lower incidence of smoking, and younger age at presentation of the disease allowing earlier medical treatment.

Nevertheless, the influence of obesity on overall mortality in chronic HF remains unclear and it is still debated if there is an intrinsic association between obesity and mortality in HF subjects, or whether the obesity paradox is confounded by other uncontrolled factors contributing to its existence $[14,15]$.

Furthermore, most studies demonstrating the obesity paradox have used body mass index (BMI), and less commonly measures of central obesity, as an index of overweight and obesity in HF [16]. Nevertheless, BMI may not be a good way to correct weight for height. Accordingly, potential methods for describing body size such as body surface area (BSA), commonly used for indexing physiologic parameters associated with HF, may correlate more closely with prognosis in HF.

The objective of the current study was to investigate the prognostic significance of BSA, in comparison with BMI, as markers of body habitus in a cohort of chronic systolic HF subjects evaluated at their initial visit to the HF clinic. In addition, we aimed to determine whether the association between obesity and mortality is influenced by common confounders.

\section{Methods}

\section{Study population}

The study population included 637 consecutive chronic systolic HF patients, defined as left ventricular ejection fraction $(\mathrm{LVEF})<40 \%$. Seven patients had BMI $<18.5 \mathrm{~kg} / \mathrm{m}^{2}$ and were excluded from data analysis due to a small group size of underweight patients. All subjects had documented BMI and BSA measurements carried out at their initial visit to a tertiary outpatient HF clinic. BSA was calculated according to the Mosteller formula [weight $(\mathrm{kg}) \times$ height $(\mathrm{cm}) / 3600]^{1 / 2}[17]$. Mosteller formula is recommended as an accurate measure to estimate BSA, and is commonly used due to its simplicity and applicability in both clinical and laboratory medicine [18]. Patients were categorized according to tertiles of BSA $[\mathrm{T} 1 \leq 1.79$; $1.79<\mathrm{T} 2 \leq 1.99 ; \mathrm{T} 3>1.99]$ and BMI $\left(\mathrm{kg} / \mathrm{m}^{2}\right)$ $[\mathrm{T} 1 \leq 25.5 ; 25.5<\mathrm{T} 2 \leq 30.4$; $\mathrm{T} 3>30.4]$.

Baseline characteristics and co-morbidities were recorded in all patients, including age, gender, presence of hypertension, diabetes mellitus, coronary artery disease, paroxysmal/permanent atrial fibrillation, New York Heart Association (NYHA) grade, laboratory values of hemoglobin and creatinine, and treatment with beta-blockers, angiotensin converting enzyme blockers or angiotensin receptor blockers (ACEI/ARBs). QRS segment width (ms) was recorded from electrocardiogram tracings; LVEF and left atrial dimension were assessed by 2-dimensional echocardiographic studies. Data concerning all-cause mortality during the follow-up period were gathered from patients' electronic files and computerized records of health maintenance organizations.

The study was approved by the Lady Davis Carmel Medical Center Institutional Review Board.

\section{Data analysis}

Continuous data are presented as means \pm standard deviation, and categorical variables as numbers or percentages. The $\chi^{2}$ test was used to compare categorical variables. Kruskal-Wallis test and one-way analysis of variance (ANOVA) test were used to compare continuous variables where appropriate. Survival curves were plotted by the Kaplan-Meier method using the log-rank test for assessing the significance of the differences in survival between tertiles in each comparison.

In order to assess the prognostic value of $\mathrm{BMI}$ and BSA, the patients were divided into tertiles based on their BMI or BSA, and a multivariate analysis was performed using the Cox proportional-hazards regression analysis with the tertile index serving as the explanatory variable. Hazard ratios (HR) for death were calculated according to tertiles of both BMI and BSA, with $95 \%$ confidence intervals (CI). Adjustment was made for gender and other risk factors and baseline characteristics by adding them as covariates to 
the multivariate model. Cut-off for inclusion into the multivariate model was a univariate $\mathrm{p}<0.10$. The substantial effect of age on the association between obesity and mortality was examined in a separate model.

The results were considered statistically significant when the $\mathrm{p}$-value was $<0.05$. The SPSS statistical software version 20.0 was used to perform all statistical analyses.

\section{Results}

There were 630 consecutive patients $(80 \%$ male) with systolic HF included in the study. Mean age was $65 \pm 13$ years. The mean LVEF of the study population was $26 \pm 7 \%$ and $53 \%$ had NYHA functional class III/IV at their initial index visit to the HF clinic.

Mean BMI level was $28.5 \pm 5.2 \mathrm{~kg} / \mathrm{m}^{2}$ (median 27.6) and mean BSA level was $1.90 \pm 0.22 \mathrm{~m}^{2}$ (median 1.88). Baseline clinical characteristics, according to BSA and BMI tertiles are presented in Table 1. Higher tertiles of BSA and BMI were both associated with younger age, higher rates of diabetes, left atrial enlargement and elevated hemoglobin levels. In addition, upper teritle of BMI, but not BSA, was associated with increased incidence of hypertension and a small but statistically significant increase in LVEF. Despite the widespread use of beta-blockers in the entire study cohort, a variance was noted between subgroups, showing a tendency towards increased use of betablockers in subjects with higher indices of body habitus (Table 1).

During a mean follow-up period of $39 \pm 26$ months (median 35), 248 (39\%) patients died. Mortality during the follow-up period was most prevalent in subjects in the low tertile of BSA and BMI ( $47 \%$ and $48 \%$, respectively), less prevalent in the mid tertile ( $41 \%$ and $37 \%$ ) and lowest in the high tertile subjects $(31 \%$ and $32 \%, \mathrm{p}=0.002)$. Absolute mortality rates were not significantly different between moderately obese (BMI 30-35 $\left.\mathrm{kg} / \mathrm{m}^{2}\right)$ and severely obese $\left(\right.$ BMI $\left.>35 \mathrm{~kg} / \mathrm{m}^{2}\right)$ patients $(49 / 139,35 \%$ vs. $24 / 84,29 \%$; $\mathrm{p}=0.38)$. Mortality was not's Figures 1 and 2 show KaplanMeier survival curves according to tertiles of both BMI and BSA. Long-term mortality was inversely and progressively associated with body habitus, illustrating the obesity paradox (log-rank test $\mathrm{p}<0.001)$.

Hazard ratios for all-cause mortality are presented in Table 2 for each tertile of BSA and BMI.
Compared to the highest tertile of BSA (T3: reference group), subjects in the lower BSA tertiles had significantly increased risk for mortality in an inclining pattern (T2: $\mathrm{HR}=1.41,95 \%$ CI 1.01-1.95, $\mathrm{p}=0.04$ and $\mathrm{T} 1: \mathrm{HR}=1.78,95 \%$ CI $1.29-2.45$, $\mathrm{p}<0.001)$. After multivariate adjustment including hypertension, history of myocardial infarction, LVEF, permanent/paroxysmal atrial fibrillation, left atrial dimension, QRS segment width, hemoglobin and creatinine levels, NYHA grade, beta-blockers and ACEI/ARBs treatment, the inverse association between BSA and mortality was weakened (Table 2), and did not persist after adding age to the multivariate model. Moreover, even after adjustment for age alone the inverse association between BSA and mortality disappeared (T3: reference; T2: HR $=0.96,95 \%$ CI $0.68-1.35, \mathrm{p}=0.82$; T1: $\mathrm{HR}=1.15,95 \%$ CI 0.82-1.63, $\mathrm{p}=0.42$ ). A similar pattern of relationship was seen between BMI and mortality risk (Table 2). In addition, when BSA and BMI were analyzed as continuous variables, paradoxical association with all-cause mortality was seen, but did not persist after adjustment for age (data not shown).

After dividing the study population to subgroups according to tertiles of age, no significant differences in all-cause mortality were seen between BSA tertiles, in any of the age groups (Fig. 3).

\section{Discussion}

In the current analysis, both BMI and BSA, a common measure of body size used for indexing physiologic parameters (mainly hemodynamic), were similarly inversely associated with mortality and provided prognostic information in systolic $\mathrm{HF}$ patients. The significant paradoxical association between both measures reflecting body habitus and mortality was eliminated after adjustment for age alone, but not after adjustment for other covariates including comorbidities, laboratory blood tests and drug therapies. Accordingly, the obesity paradox in HF may be significantly confounded by the younger age of the obese patients.

The obesity paradox in HF has been consistently demonstrated in multiple observational studies including meta-analysis and has been observed especially with BMI [4-9]. However, $\mathrm{BMI}$ is not a direct measure of obesity and is not an accurate way to correct weight for height. BSA correlates more closely to physiologic parameters than body weight. It is commonly used 
Table 1. Patient characteristics according to tertiles of body mass index (BMI) and body surface area (BSA).

\begin{tabular}{|c|c|c|c|c|c|c|c|c|c|}
\hline \multirow[t]{2}{*}{ Variable } & \multirow{2}{*}{$\begin{array}{c}\text { All subjects } \\
(n=630)\end{array}$} & \multicolumn{3}{|c|}{ BMI } & \multicolumn{5}{|c|}{ BSA } \\
\hline & & T1 & T2 & T3 & $\mathbf{P}$ & T1 & T2 & T3 & $\mathbf{P}$ \\
\hline Gender (male) & $\begin{array}{c}505 \\
(80 \%)\end{array}$ & $\begin{array}{c}174 \\
(82 \%)\end{array}$ & $\begin{array}{c}173 \\
(82 \%)\end{array}$ & $\begin{array}{c}158 \\
(77 \%)\end{array}$ & 0.32 & $\begin{array}{c}138 \\
(66 \%)\end{array}$ & $\begin{array}{c}168 \\
(80 \%)\end{array}$ & $\begin{array}{c}199 \\
(95 \%)\end{array}$ & $<0.001$ \\
\hline Age [years] & $65 \pm 13$ & $67 \pm 15$ & $66 \pm 12$ & $62 \pm 12$ & 0.001 & $69 \pm 14$ & $67 \pm 12$ & $59 \pm 12$ & $<0.001$ \\
\hline Height [cm] & $1.67 \pm 0.09$ & $1.67 \pm 0.08$ & $1.66 \pm 0.09$ & $1.66 \pm 0.09$ & 0.68 & $\begin{array}{l}1.60 \pm \\
\pm 0.08\end{array}$ & $\begin{array}{l}1.67 \pm \\
\pm 0.07\end{array}$ & $\begin{array}{l}1.72 \pm \\
\pm 0.07\end{array}$ & $<0.001$ \\
\hline Weight [kg] & $79.1 \pm 16.3$ & $65 \pm 8$ & $77 \pm 10$ & $95 \pm 13$ & $<0.001$ & $63 \pm 6$ & $77 \pm 5$ & $97 \pm 11$ & $<0.001$ \\
\hline Hypertension & $\begin{array}{c}375 \\
(59 \%)\end{array}$ & $\begin{array}{c}105 \\
(49 \%)\end{array}$ & $\begin{array}{c}125 \\
(59 \%)\end{array}$ & $\begin{array}{c}145 \\
(70 \%)\end{array}$ & $<0.001$ & $\begin{array}{c}121 \\
(58 \%)\end{array}$ & $\begin{array}{c}128 \\
(61 \%)\end{array}$ & $\begin{array}{c}126 \\
(60 \%)\end{array}$ & 0.66 \\
\hline $\begin{array}{l}\text { Diabetes } \\
\text { mellitus }\end{array}$ & $\begin{array}{c}281 \\
(44 \%)\end{array}$ & $\begin{array}{c}72 \\
(34 \%)\end{array}$ & $\begin{array}{c}95 \\
(45 \%)\end{array}$ & $\begin{array}{c}114 \\
(55 \%)\end{array}$ & $<0.001$ & $\begin{array}{c}76 \\
(36 \%)\end{array}$ & $\begin{array}{c}100 \\
(47 \%)\end{array}$ & $\begin{array}{c}105 \\
(50 \%)\end{array}$ & 0.012 \\
\hline $\begin{array}{l}\text { Myocardial } \\
\text { infarction }\end{array}$ & $\begin{array}{c}384 \\
(61 \%)\end{array}$ & $\begin{array}{c}123 \\
(58 \%)\end{array}$ & $\begin{array}{c}139 \\
(66 \%)\end{array}$ & $\begin{array}{c}122 \\
(59 \%)\end{array}$ & 0.19 & $\begin{array}{c}121 \\
(58 \%)\end{array}$ & $142(67 \%)$ & $\begin{array}{c}121 \\
(58 \%)\end{array}$ & 0.07 \\
\hline $\begin{array}{l}\text { Atrial } \\
\text { fibrillation }\end{array}$ & $\begin{array}{c}195 \\
(31 \%)\end{array}$ & $\begin{array}{c}66 \\
(31 \%)\end{array}$ & $\begin{array}{c}63 \\
(30 \%)\end{array}$ & $\begin{array}{c}66 \\
(32 \%)\end{array}$ & 0.89 & $\begin{array}{c}60 \\
(29 \%)\end{array}$ & $\begin{array}{c}74 \\
(35 \%)\end{array}$ & $\begin{array}{c}61 \\
(29 \%)\end{array}$ & 0.28 \\
\hline LVEF [\%] & $25.8 \pm 7.3$ & $24.7 \pm 7.1$ & $25.5 \pm 7.2$ & $27.1 \pm 7.4$ & 0.003 & $\begin{array}{c}25.4 \pm \\
\pm 7.4\end{array}$ & $\begin{array}{r}26.2 \pm \\
\pm 7.4\end{array}$ & $\begin{array}{r}25.7 \pm \\
\pm 7.1\end{array}$ & 0.58 \\
\hline $\begin{array}{l}\text { Left atrium } \\
{[\mathrm{cm}]}\end{array}$ & $4.5 \pm 0.6$ & $4.4 \pm 0.6$ & $4.5 \pm 0.5$ & $4.6 \pm 0.6$ & 0.03 & $4.4 \pm 0.6$ & $4.5 \pm 0.6$ & $4.6 \pm 0.6$ & $<0.001$ \\
\hline $\begin{array}{l}\text { QRS width } \\
\text { [ms] }\end{array}$ & $129 \pm 36$ & $132 \pm 39$ & $128 \pm 36$ & $126 \pm 33$ & 0.21 & $129 \pm 36$ & $132 \pm 40$ & $126 \pm 31$ & 0.19 \\
\hline $\begin{array}{l}\text { Creatinine [mg/ } \\
\mathrm{dL}]\end{array}$ & $1.37 \pm 0.72$ & $1.40 \pm 0.71$ & $1.38 \pm 0.75$ & $1.33 \pm 0.71$ & 0.61 & $\begin{array}{l}1.37 \pm \\
\pm 0.72\end{array}$ & $\begin{array}{l}1.41 \pm \\
\pm 0.78\end{array}$ & $\begin{array}{l}1.33 \pm \\
\pm 0.66\end{array}$ & 0.48 \\
\hline $\begin{array}{l}\text { Hemoglobin } \\
{[\mathrm{mg} / \mathrm{dL}]}\end{array}$ & $12.7 \pm 1.7$ & $12.3 \pm 1.7$ & $12.8 \pm 1.7$ & $12.9 \pm 1.7$ & 0.01 & $\begin{array}{c}12.3 \pm \\
\pm 1.6\end{array}$ & $\begin{array}{r}12.6 \pm \\
\pm 1.7\end{array}$ & $\begin{array}{r}13.1 \pm \\
\pm 1.7\end{array}$ & 0.01 \\
\hline ACEI or ARBs & $\begin{array}{c}555 \\
(88 \%)\end{array}$ & $\begin{array}{c}182 \\
(85 \%)\end{array}$ & $\begin{array}{c}188 \\
(89 \%)\end{array}$ & $\begin{array}{c}185 \\
(89 \%)\end{array}$ & 0.33 & $\begin{array}{c}182 \\
(87 \%)\end{array}$ & $\begin{array}{c}182 \\
(86 \%)\end{array}$ & $\begin{array}{c}191 \\
(91 \%)\end{array}$ & 0.28 \\
\hline Beta-blockers & $\begin{array}{c}589 \\
(93 \%)\end{array}$ & $\begin{array}{c}191 \\
(90 \%)\end{array}$ & $\begin{array}{c}203 \\
(96 \%)\end{array}$ & $\begin{array}{c}195 \\
(94 \%)\end{array}$ & 0.037 & $\begin{array}{c}188 \\
(90 \%)\end{array}$ & $\begin{array}{c}200 \\
(95 \%)\end{array}$ & $\begin{array}{c}201 \\
(96 \%)\end{array}$ & 0.037 \\
\hline NYHA grade & $2.6 \pm 0.8$ & $2.6 \pm 0.9$ & $2.6 \pm 0.8$ & $2.6 \pm 0.8$ & 0.88 & $2.6 \pm 0.8$ & $2.7 \pm 0.8$ & $2.5 \pm 0.8$ & 0.19 \\
\hline $\begin{array}{l}\text { All-cause } \\
\text { mortality }\end{array}$ & $\begin{array}{c}248 \\
(39 \%)\end{array}$ & $\begin{array}{c}103 \\
(48 \%)\end{array}$ & $\begin{array}{c}79 \\
(37 \%)\end{array}$ & $\begin{array}{c}66 \\
(32 \%)\end{array}$ & 0.002 & $\begin{array}{c}98 \\
(47 \%)\end{array}$ & $\begin{array}{c}86 \\
(41 \%)\end{array}$ & $\begin{array}{c}64 \\
(31 \%)\end{array}$ & 0.002 \\
\hline
\end{tabular}

ACEI/ARBs - angiotensin converting enzyme blockers or angiotensin receptor blockers; LVEF — left ventricular ejection fraction; NYHA — New York Heart Association

in medicine, in research and clinical practice, as a biometric unit to adjust size, mass and volume, in individuals with $\mathrm{HF}$ at different body sizes $[18,19]$. BSA was also shown to be an outcome predictor. A very small BSA was found to be an independent predictor of worse mortality after coronary artery bypass surgery [20]. In another study, adult candidates for heart transplantation with lower BSA, including most female patients, had worse prognosis [21]. In the present study, increased body size was associated with better survival of patients with chronic systolic HF. BSA was a good predictor of survival, at least as BMI, and even after multifactorial adjustment including gender. These findings are in accordance with the results of a study by Futter et al. [22], reporting that BSA was a strong predictor of mortality in $\mathrm{HF}$, better than other measures of body habitus and irrespective of height correction. The authors concluded that the greater the overall bulk of the body, the better the survival, and that meeting the increased metabolic demand of chronic HF 


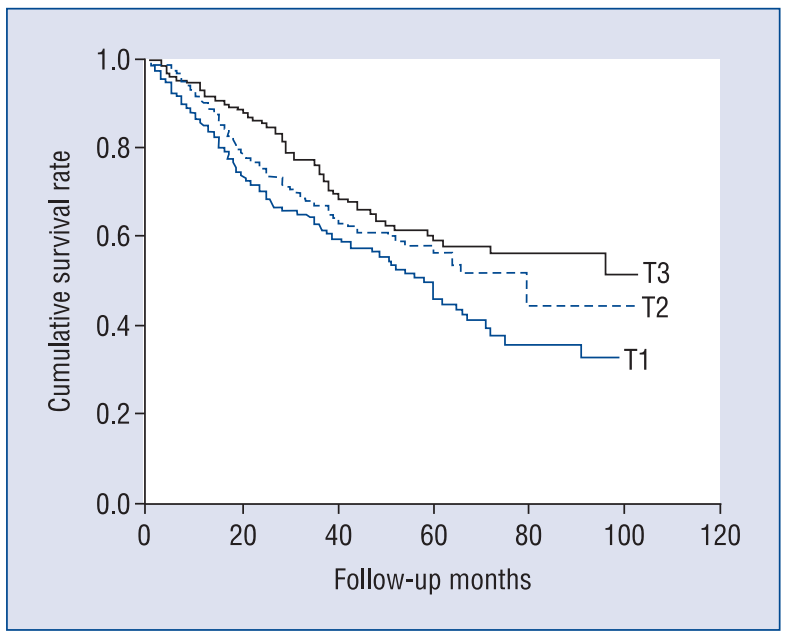

Figure 1. Survival according to tertiles of body mass index (BMI); Kaplan-Meier estimates of survival in patients with systolic heart failure, according to tertiles of BMI (T1-T3). Mean BMI level was $28.5 \pm 5.2 \mathrm{~kg} / \mathrm{m}^{2}$ $(\mathrm{T} 1,23.3 \pm 17 ; \mathrm{T} 2,27.8 \pm 1.4 ; \mathrm{T} 3,34.6 \pm 3.6)$; log-rank $\mathrm{p}<0.001$.

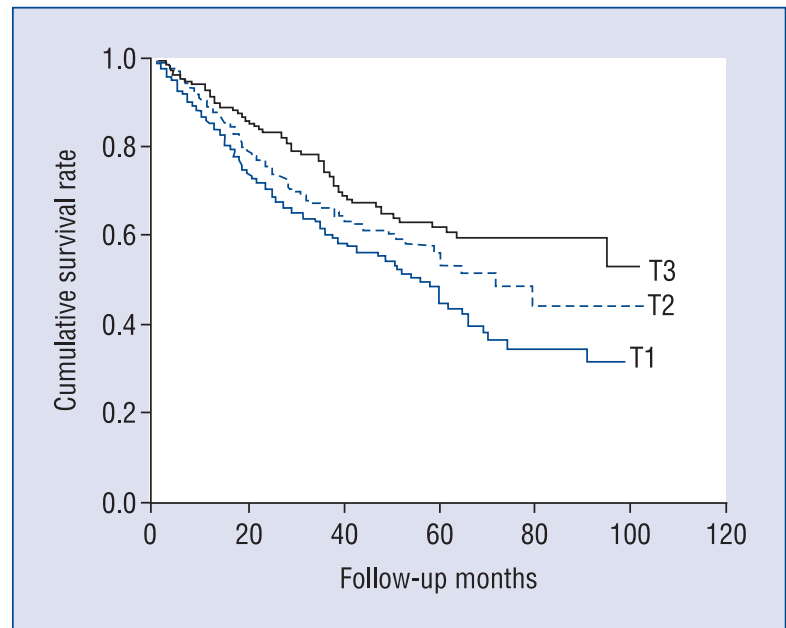

Figure 2. Survival according to tertiles of body surface area (BSA); Kaplan-Meier estimates of survival in patients with systolic heart failure, according to tertiles of BSA (T1-T3). Mean BSA level was $1.90 \pm 0.22 \mathrm{~m}^{2}(\mathrm{~T} 1,1.67 \pm$ $\pm 0.09 ; \mathrm{T} 2,1.88 \pm 0.06 ; \mathrm{T} 3,2.15 \pm 0.13)$; log-rank $\mathrm{p}<0.001$.

Table 2. Hazard ratios (HR) for mortality risk according to tertiles of body mass index (BMI) and body surface area (BSA).

\begin{tabular}{lccccc}
\hline $\begin{array}{l}\text { Vari- } \\
\text { able }\end{array}$ & $\begin{array}{c}\text { Ter- } \\
\text { tile }\end{array}$ & Unadjusted HR & $\begin{array}{c}\text { Multivariate* } \\
\text { adjusted HR }\end{array}$ & $\begin{array}{c}\text { Multivariate* + age } \\
\text { adjusted HR }\end{array}$ & $\begin{array}{c}\text { Age only } \\
\text { adjusted HR }\end{array}$ \\
\hline $\begin{array}{l}\text { BSA } \\
\text { tertiles }\end{array}$ & T3 & 1 (reference) & 1 (reference) & 1 (reference) & 1 (reference) \\
& T2 & $\begin{array}{c}1.41(1.01-1.95), \\
p=0.04\end{array}$ & $\begin{array}{c}1.21(0.86-1.70), \\
p=0.27\end{array}$ & $\begin{array}{c}0.94(0.66-1.32), \\
p=0.71\end{array}$ & $\begin{array}{c}0.96(0.68-1.35), \\
p=0.82\end{array}$ \\
& T1 & $\begin{array}{c}1.78(1.29-2.45), \\
p<0.001\end{array}$ & $\begin{array}{c}1.69(1.21-2.35), \\
p=0.002\end{array}$ & $\begin{array}{c}1.06(0.74-1.50), \\
p=0.76\end{array}$ & $\begin{array}{c}1.15(0.82-1.63), \\
p=0.42\end{array}$ \\
BMI & T3 & 1 (reference) & 1 (reference) & 1 (reference) & 1 (reference) \\
tertiles & T2 & $1.29(0.92-1.79)$, & $1.18(0.84-1.66)$, & $1.02(0.73-1.44)$, & $1.13(081-1.58)$, \\
& & $p=0.13$ & $p=0.33$ & $p=0.89$ & 0.47 \\
& T1 & $1.66(1.21-2.27)$, & $1.51(1.10-2.08)$, & $1.11(0.79-1.55)$, & $1.30(0.94-1.80)$, \\
& & $p=0.002$ & $p=0.012$ & $p=0.56$ & $p=0.12$ \\
\hline
\end{tabular}

*Multivariate Cox regression analysis. Adjusted for gender, hypertension, history of myocardial infarction, left ventricular ejection fraction, permanent/paroxysmal atrial fibrillation, left atrial dimension, QRS width, hemoglobin and creatinine level, NYHA grade, beta blockers and ACEI/ARBs treatment.

is likely to be more readily sustained with an increased body reserve.

The concept of the obesity paradox in HF is controversial, and different studies present conflicting results. It is debated whether obesity itself may be protective in HF due to factors such as less cachexia and inflammatory activation, or whether BMI is confounded by other residual factors impacting mortality [23-26]. Studies reporting the obesity paradox reveal substantial differences in demographic and clinical characteristics of obese vs. non-obese HF patients [13]. Not infrequently obese HF individuals are younger, have higher systolic blood pressure, better renal function, higher LVEF, better nutritional status, and less anemia. Therefore, baseline characteristics favoring patients with higher BMI or BSA may be the foundation to their better survival.

In the current study, age was the most significant confounder, apparently abolishing the obesity paradox seen in systolic HF. Additional study investigating the association between obesity 


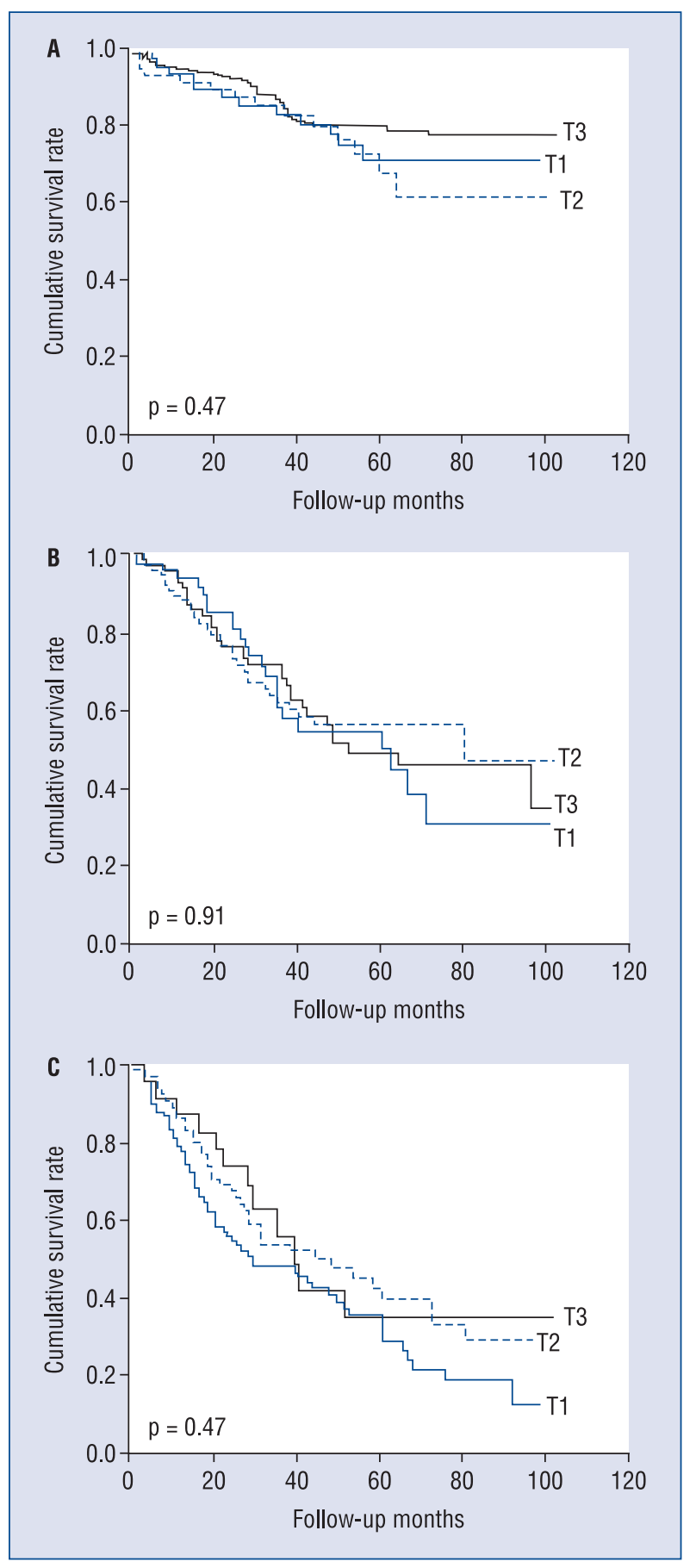

Figure 3. Survival according to body surface area (BSA) tertiles (T1-T3), in three age groups; Kaplan-Meier estimates of survival in patients with systolic heart failure, in three age groups (age tertiles: age $\leq 60$ years $(A)$; $60<$ age $\leq 73$ years $(B)$; age $>73$ years $(C)$, according to tertiles of BSA (T1-T3); log-rank $p=$ non-significant in all subgroups.

and outcomes in post-acute myocardial infarction patients with systolic HF, concluded similarly that the paradoxical unadjusted survival associated with obesity is largely explained by the younger age of the obese patients, suggesting that there may be no intrinsic association between obesity and mortality [27]. In a recent manuscript reviewing the obesity paradox in HF, Guglin et al. [13] reported a significant difference in age of obese and nonobese HF patients. In 17 out of 19 studies reporting obesity paradox, higher BMI values were found in younger HF patients [13]. The authors suggested that younger age, which is certainly associated with longevity, is associated with many variables which not all could simply be accounted for. Therefore, customary statistical manipulations aimed at removing the age difference may be limited, leading to lack of uniformity in study results.

\section{Limitations of the study}

Our study has several limitations. Underweight patients were not included in the study due to small sample size, and thus the impact of cardiac cachexia may not have been truly accounted for. BSA has different formulas, some of which are complex to calculate and might have impacted differently on study results. Lower BSA in female patients can also be caused by a group effect because of their smaller body size. However, in the current study, the obesity paradox was not affected by adjustment to gender, and the study population was predominantly male.

We did not have data on other factors that could have also effect on survival in systolic HF, such as smoking status and the use of implantable cardioverter-defibrillators. Finally, the study was conducted in a single center and included predominantly advanced systolic HF patients. Therefore, study results may not be generalized to other cohorts of HF population.

\section{Conclusions}

In conclusion, BSA provided prognostic information at least as good as BMI in systolic HF, showing an inverse association with all-cause mortality. However, the obesity paradox observed was eliminated after adjustment for age, suggesting lack of intrinsic association between body size indices and mortality in systolic HF. Conducting prospective and long-term interventional studies may result in better understanding of the obesity paradox. Moreover, the utility of BSA as a useful prognostic indicator in HF should be further investigated in future research.

Conflict of interest: None declared 


\section{References}

1. Kenchaiah S, Evans JC, Levy D et al. Obesity and the risk of heart failure. N Engl J Med, 2002; 347: 305-313.

2. Levitan EB, Yang AZ, Wolk A, Mittleman MA. Adiposity and incidence of heart failure hospitalization and mortality: A population-based prospective study. Circ Heart Fail, 2009; 2: 202-208.

3. Hubert HB, Feinleib M, McNamara PM, Castelli WP. Obesity as an independent risk factor for cardiovascular disease: A 26-year follow-up of participants in the Framingham Heart Study. Circulation, 1983; 67: 968-977.

4. Horwich T, Fonarow G, Hamilton MA, MacLellan WR, Woo MA, Tillisch JH. The relationship between obesity and mortality in patients with heart failure. J Am Coll Cardiol, 2001; 38: 789-795.

5. Lavie CJ, Osman AF, Milani RV, Mehra MR: Body composition and prognosis in chronic systolic heart failure: The obesity paradox. Am J Cardiol, 2003; 91: 891-894.

6. Bozkurt B, Deswal A: Obesity as a prognostic factor in chronic symptomatic heart failure. Am Heart J, 2005; 150: 1233-1239 .

7. Kenchaiah S, Pocock SJ, Wang D et al.; CHARM investigators: Body mass index and prognosis in patients with chronic heart failure: Insights from the Candesartan in Heart failure: Assessment of Reduction in Mortality and morbidity (CHARM) program. Circulation, 2007; 116: 627-636.

8. Oreopoulos A, Padwal R, Kalantar-Zadeh K, Fonarow GC, Norris CM, McAlister FA. Body mass index and mortality in heart failure: A meta-analysis. Am Heart J, 2008; 156: 13-22.

9. Fonarow GC, Srikanthan P, Costanzo MR, Cintron GB, Lopatin M, ADHERE Scientific Advisory Committee and Investigators: An obesity paradox in acute heart failure: Analysis of body mass index and in-hospital mortality for 108,927 patients in the Acute Decompensated Heart Failure National Registry. Am Heart J, 2007; 153: 74-81.

10. Zafrir B, Adir Y, Shehadeh W, Shteinberg M, Salman N, Amir O. The association between obesity, mortality and filling pressures in pulmonary hypertension patients; the "obesity paradox". Respir Med, 2013; 107: 139-146.

11. Goel K, Lopez-Jimenez F, De Schutter A, Coutinho T, Lavie CJ. Obesity paradox in different populations: Evidence and controversies. Future Cardiol, 2014; 10: 81-91.

12. Lavie CJ, McAuley PA, Church TS, Milani RV, Blair SN. Obesity and cardiovascular diseases: Implications regarding fitness, fatness, and severity in the obesity paradox. J Am Coll Cardiol, 2014; 63: 1345-1354.

13. Guglin M, Baxi K, Schabath M. Anatomy of the obesity paradox in heart failure. Heart Fail Rev, 2014; 19: 621-635.
14. Lavie CJ, Ventura HO. Analyzing the weight of evidence on the obesity paradox and heart failure. Is there a limit to the madness? Congest Heart Fail, 2013; 19: 158-159.

15. Chase PJ, Davis PG, Bensimhon DR. The obesity paradox in chronic heart failure: What does it mean? Curr Heart Fail Rep, 2014; 11: 111-117.

16. Clark AL, Foranow GC, Horwich TB. Waist circumference, body mass index, and survival in systolic heart failure: The obesity paradox. J Cardiac Fail, 2011; 17: 374-380.

17. Mosteller RD. Simplified calculation of body surface area. N Engl J Med, 1987; 317: 1098.

18. Verbraecken J, Van de Heyning P, De Backer W, Van Gaal L. Body surface area in normal-weight, overweight, and obese adults. A comparison study. Metabolism, 2006; 55: 515-524.

19. Ristow B, Ali S, Na B, Turakhia MP, Whooley MA, Schiller NB. predicting heart failure hospitalization and mortality by quantitative echocardiography: Is body surface area the indexing method of choice? The Heart and Soul Study. J Am Soc Echocardiogr, 2010; 23: 406-413.

20. Habib RH, Zacharias A, Schwann TA, Riordan CJ, Durham SJ, Shah A. Effects of obesity and small body size on operative and long-term outcomes of coronary artery bypass surgery: A propensity-matched analysis. Ann Thorac Surg, 2005; 79: 1976-1986.

21. Komoda T, Drews T, Hetzer R, Lehmkuhl HB. Adult candidates for heart transplantation with larger body surface area have better prognosis on waiting list after progression to critically ill status. Eur J Cardiothorac Surg, 2011; 39: 317-320.

22. Futter JE, Cleland JG, Clark AL. Body mass indices and outcome in patients with chronic heart failure. Eur J Heart Fail, 2011; 13: 207-213.

23. Lavie CJ, Alpert MA, Arena R, Mehra MR, Milani RV, Ventura HO. Impact of obesity and the obesity paradox on prevalence and prognosis in heart failure. J Am Coll Cardiol Heart Fail, 2013; 1: 93-102.

24. Chrysant SG, Chrysant GS. New insights into the true nature of the obesity paradox and the lower cardiovascular risk. J Am Soc Hypertens, 2013; 7: 85-94.

25. Frankenstein L, Zugck C, Nelles M, Schellberg D, Katus HA, Remppis BA. The obesity paradox in stable chronic heart failure does not persist after matching for indicators of disease severity and confounders. Eur J Heart Fail, 2009; 11: 1189-1194.

26. Shah R, Gayat E, Januzzi JL Jr, Sato N, Cohen-Solal A, diSomma S. Body mass index and mortality in acutely decompensated heart failure across the world: A global obesity paradox. J Am Coll Cardiol, 2014; 63: 778-785.

27. Wu AH, Pitt B, Anker SD, Vincent J, Mujib M, Ahmed A. Association of obesity and survival in systolic heart failure after acute myocardial infarction: Potential confounding by age. Eur J Heart Fail, 2010; 12: 566-573. 